\title{
Effect of Montelukast Monotherapy on Oxidative Stress Parameters and DNA Damage in Children with Asthma
}

\author{
Fatih Dilek $^{\mathrm{a}}$ Emin Ozkaya ${ }^{\mathrm{a}}$ Abdurrahim Kocyigit ${ }^{\mathrm{c}}$ Mebrure Yazici ${ }^{\mathrm{a}}$ \\ Siddika Kesgin ${ }^{c}$ Ahmet Hakan Gedik ${ }^{b}$ Erkan Cakir ${ }^{b}$ \\ Divisions of a Pediatric Allergy and Immunology and b Pediatric Pulmonology, Department of Pediatrics, and \\ 'Department of Clinical Biochemistry, Bezmialem Vakif University Medical Faculty, Istanbul, Turkey
}

\section{Key Words}

Montelukast · Asthma · Children · Total oxidant status .

Total antioxidant status $\cdot$ DNA damage

\begin{abstract}
Background: There is ample knowledge reported in the literature about the role of oxidative stress in asthma pathogenesis. It is also known that the interaction of reactive oxygen species with DNA may result in DNA strand breaks. The aim of this study was to investigate if montelukast monotherapy affects oxidative stress and DNA damage parameters in a population of pediatric asthma patients. Methods: Group I consisted of 31 newly diagnosed asthmatic patients not taking any medication, and group II consisted of 32 patients who had been treated with montelukast for at least 6 months. Forty healthy control subjects were also enrolled in the study. Plasma total oxidant status (TOS) and total antioxidant status (TAS) were measured to assess oxidative stress. DNA damage was assessed by means of alkaline comet assay. Results: The patients in both group I and group II had statistically significant higher plasma TOS (13.1 \pm 4 and $11.1 \pm 4.1 \mu \mathrm{mol} \mathrm{H}_{2} \mathrm{O}_{2}$ equivalent/liter, respectively) and low TAS levels $(1.4 \pm 0.5$ and $1.5 \pm 0.5 \mathrm{mmol}$ Trolox equivalent/ liter, respectively) compared with the control group (TOS:
\end{abstract}

$6.3 \pm 3.5 \mu \mathrm{mol} \mathrm{H}_{2} \mathrm{O}_{2}$ equivalent/liter and TAS: $2.7 \pm 0.6 \mathrm{mmol}$ Trolox equivalent/liter; $\mathrm{p}<0.05)$. DNA damage was $18.2 \pm 1.0$ arbitrary units (a.u.) in group I, $16.7 \pm 8.2$ a.u. in group II and $13.7 \pm 3.4$ a.u. in the control group. There were statistically significant differences only between group I and the control group ( $p<0.05$ ). Conclusions: According to the findings, montelukast therapy makes only minimal but not statistically significant improvement in all TOS, TAS and DNA damage parameters.

(c) 2015 S. Karger AG, Basel

\section{Introduction}

Asthma is a common, chronic respiratory disease affecting $1-18 \%$ of people in different countries. It is characterized by variable symptoms of wheeze, shortness of breath, chest tightness, cough and variable expiratory airflow limitation [1]. Reactive oxygen species (ROS) generated from inflammatory/resident cells play an important role in asthma pathogenesis $[2,3]$. ROS can cause airway hyperresponsiveness, mucus hypersecretion, increased vascular permeability, synthesis and release of chemoattractants, the release of neuropeptides and impairment in the responsiveness of $\beta$-adrenergic receptors [4].

\section{KARGER 125}

(c) 2015 S. Karger AG, Base

$1018-2438 / 15 / 1672-0119 \$ 39.50 / 0$

E-Mail karger@karger.com

www.karger.com/iaa
Correspondence to: Dr. Fatih Dilek

Division of Pediatric Allergy and Immunology, Department of Pediatrics Bezmialem Vakif University Medical Faculty, Adnan Menderes Bulvari Vatan Caddesi TR-34093 Fatih/Istanbul (Turkey)

E-Mail drfatihdilek@yahoo.com 
Studies have shown that inflammation is accompanied by the upregulation of an inducible isoform of nitric oxide (NO) synthase that is capable of producing excess NO for a prolonged period. It has been proposed that damage to DNA and tissue induced by ROS and NO-derived reactive nitrogen species may contribute to increased mutation rates, genome instability, apoptosis and the associated tissue regeneration and cell proliferation, all of which can drive allergic diseases such as asthma [4-8]. Eosinophils play a major role in ROS generation in the asthmatic airways [3]. Cysteinyl leukotrienes (LTs) can stimulate the proliferation of eosinophil hematopoietic progenitor cells and play a role in leukocyte migration from bone marrow to the circulation [9-11]. Cysteinyl LTs are chemoattractants for eosinophils and can increase eosinophil survival time [11-13]. Eosinophil superoxide anion generation is induced by LT $\mathrm{D}_{4}[14]$. All these effects of cysteinyl LTs can be blocked by LT receptor antagonists in vivo $[11,15,16]$. In recent years, a growing body of evidence suggests that activity of NADPH oxidase (NOX) is stimulated by $\mathrm{LT}_{4}$ via the $\mathrm{LT} \mathrm{B}_{4}$ receptor 2 (BLT2). BLT2-stimulated NOX1 upregulation is a downstream signaling route that mediates the synthesis of Th2 cytokines (IL-4 and IL-13) and the generation of NOX1-derived ROS $[17,18]$.

There are many studies and reviews published on the role of oxidative stress in pathogenesis asthma, but reports on the capacity of asthma treatment to reduce oxidative stress are limited [19-21]. Likewise, although there are some reports that show that allergic diseases can cause increased DNA damage, there are only a few reports assessing if treatment alters such damage [22-24]. Apart from 1 in vitro study, there is no information on whether montelukast monotherapy can overcome oxidative stress in asthma [25]. Total oxidant status (TOS) and total antioxidant status (TAS) are rapid, easy, reliable and sensitive methods for assessing oxidative stress [26, 27]. We hypothesized that montelukast monotherapy can reduce oxidative stress, as demonstrated in in vitro studies, and also reduce DNA damage, which can be measured by the TOS and TAS methods and the comet assay in children with asthma.

\section{Material and Methods}

\section{Study Groups}

A total of 94 children with mild persistent asthma were recruited from the Pediatric Allergy and Immunology Department, Bezmialem Vakif University Medical Faculty, between July and October 2014. We excluded 8 children whose parents did not con- sent to their participation in the study, 7 with a history of maternal or paternal smoking, 3 with a history of antiasthmatic drug therapy before being referred to us, 9 who were unable to comply with the drug-dosing regimen and 4 who were noncompliant (i.e. they did not come to their appointments). The clinical diagnosis, severity and control status of asthma were determined using the criteria defined in the Global Initiative for Asthma (GINA) guidelines. All of the remaining 63 children were evaluated for the presence and duration of asthma symptoms using a standard questionnaire. The questionnaire was created from patterns of respiratory symptoms that are characteristic of asthma that appear in the GINA guidelines (i.e. the presence of more than one respiratory symptom, often worse at night or early morning, varying over time and in intensity and triggered by viral infections or exercise). Patients were considered symptomatic from the date of the first appearance of any of these patterns.

Group I consisted of 31 patients newly diagnosed with asthma who had not been on any antiasthmatic therapy. We examined their medical records and applied a standard questionnaire to ensure that they had not used any antiasthmatic drugs, including inhaled or nebulized corticosteroids, montelukast, theophylline or ketotifen. A short course ( $<5$ days) of $\beta_{2}$ agonist treatment only was allowed, but not in the month prior to the study. If it was detected that patients had received an antiasthmatic drug, they were excluded from the study. Group II consisted of 32 patients who had been taking montelukast (as a monotherapy) regularly for at least 6 months. Patients were enrolled only if, apart from montelukast, the only other asthma medication was inhaled salbutamol less than $2 \times$ /week for relief, as needed. All group II children had had mild persistent asthma during the previous 6 months according to the GINA guidelines, and none had experienced asthma attacks in the last month. These patients visited the same outpatient clinic regularly every 2 months. All group II children (i.e. the study group) were taking montelukast sodium (SINGULAIR $^{\circledR}$, MSD, Kenilworth, N.J., USA) oral tablets (4 and $5 \mathrm{mg}$ ) for at least 6 months according to the manufacturer's recommendations. Their compliance was evaluated every 2 months by observing the drug package and by having the patient's mother sign a diary card showing that the medicine had been taken. If the drug was not taken for $>10 \%$ of the scheduled doses, the patient was considered to be noncompliant with therapy and was excluded from the study. We examined all patients' medical records and conducted an extensive interview with a standard questionnaire (mentioned above) at every appointment to ensure that none of them was receiving any treatment that had not been reported to the researchers.

Subjects with infectious or inflammatory diseases, a history of maternal or paternal smoking, on other medication (e.g. poly-vitamins, mineral supplements, analgesics and mucolytics) or who were overweight or obese (BMI: $>85$ th percentile) were excluded from the study. The control group comprised 40 healthy children who were periodically attending pediatric clinics at the same hospital for regular checkups of their development. Children were included in the control group if they had no history of any allergic disease or paternal or maternal smoking and were not on any medication. The study was performed in accordance with the Declaration of Helsinki and good clinical practice, and was approved by the Bezmialem Vakif University Ethical Committee (No. 71306642/050-01-04). Informed consent was obtained from the parents of all study participants. 
Fig. 1. Comet slides: there is no DNA damage in the control group patient (a) and variable degrees of DNA damage in the group I patient (b).
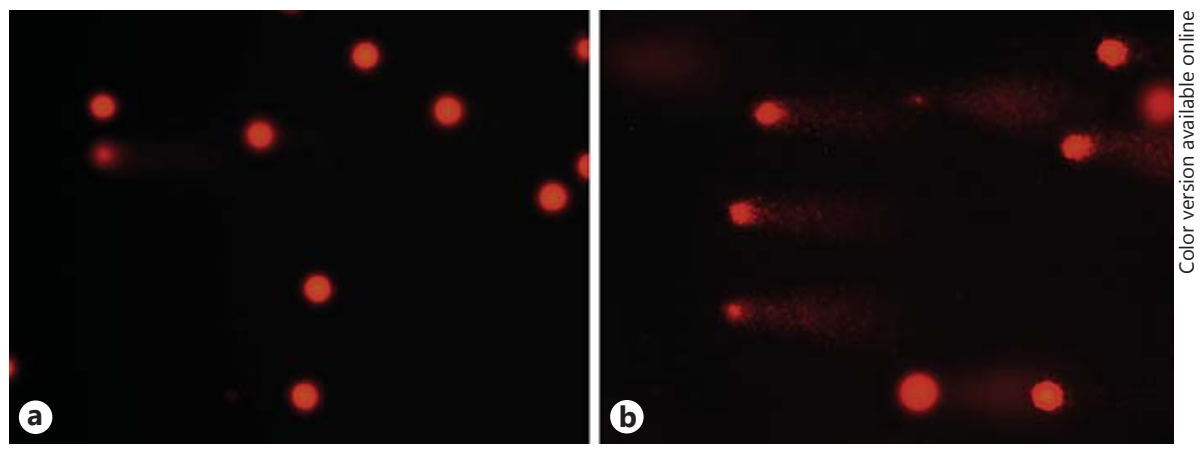

Skin-Prick Test

A prick test for aeroallergen sensitivity was performed using lancets (Stallerpoint, Paris, France), providing a standard puncture of $1 \mathrm{~mm}$. Commercial allergen solutions manufactured by Stallergenes (Paris, France) were used for the test. A total of 20 different aeroallergens, consisting of house-dust mite, grass and tree pollens, fungi and animal dander were tested. The skin-prick test was considered to be positive if a wheal appeared with a maximum diameter of $3 \mathrm{~mm}$ once the negative value had been subtracted.

\section{Lung Function Studies}

Forced expiratory volume in $1 \mathrm{~s}\left(\mathrm{FEV}_{1}\right)$ rates were measured with dynamic spirometry (Vitalograph ${ }^{\circledR}$; G.W. Berg \& Co., Buckingham, UK). The best of three successful maneuvers was recorded. The normal lung function test reference values according to Polgar and Promadhat [28] were used to generate the predicted values.

\section{Blood Sample Collection and Preparation of Cells}

Montelukast was discontinued $24 \mathrm{~h}$ before blood sampling. After overnight fasting, peripheral blood samples $(6 \mathrm{ml})$ were collected from an antecubital vein into heparinized tubes, stored at $2-4^{\circ} \mathrm{C}$ in the dark to prevent further DNA damage and processed within $2 \mathrm{~h}$. Mononuclear leukocyte isolation for the comet assay was performed by centrifugation on Histopaque 1077 (Sigma). About $1 \mathrm{ml}$ of heparinized blood was carefully layered over $1 \mathrm{ml}$ of Histopaque and centrifuged for $35 \mathrm{~min}$ at $500 \mathrm{~g}$ and $25^{\circ} \mathrm{C}$. The interface band containing mononuclear leukocytes was washed with PBS and then collected after $15 \mathrm{~min}$ of centrifugation at $400 \mathrm{~g}$. The resulting pellets were resuspended in PBS. Membrane integrity was assessed by means of the Trypan blue exclusion method. The remaining blood was centrifuged at $1,500 \mathrm{~g}$ for $10 \mathrm{~min}$ to obtain the plasma. The separated plasma was then stored at $-80^{\circ} \mathrm{C}$ until further analysis of the TAS and TOS levels.

\section{Determination of DNA Damage Using the Alkaline Comet \\ Assay}

The comet assay, also known as the single-cell gel electrophoresis assay, was performed as described by Singh et al. [29], with the following modifications: $10 \mu \mathrm{l}$ of fresh mononuclear leukocyte cell suspension (approx. 20,000 cells) was mixed with $80 \mu \mathrm{l}$ of $0.6 \%$ low-melting-point agarose in $\mathrm{PBS}$ at $37^{\circ} \mathrm{C}$. Next, $80 \mu \mathrm{l}$ of each mixture was layered onto a slide precoated with a thin layer of $1 \%$ normal-melting-point agarose and immediately covered with a coverslip. Slides were held for $5 \mathrm{~min}$ at $4{ }^{\circ} \mathrm{C}$ to allow the agarose to solidify. After removal of the coverslips, the slides were immersed in freshly prepared, cold $\left(4^{\circ} \mathrm{C}\right)$ lysing solution $[2.5 \mathrm{M} \mathrm{NaCl}, 100$ mM Na $\mathrm{N}_{2}$ EDTA, $10 \mathrm{mM}$ Tris-HCl, $1 \%$ Triton X-100 and 10\% DMSO (added just before use); $\mathrm{pH}$ 10-10.5] for at least $1 \mathrm{~h}$. They were next immersed in freshly prepared alkaline electrophoresis buffer $\left(0.3 \mathrm{M} \mathrm{NaOH}\right.$ and $\left.1 \mathrm{mM} \mathrm{Na} \mathrm{EDTA}_{2} \mathrm{pH}>13\right)$ at $4^{\circ} \mathrm{C}$ to allow the DNA to unwind ( $40 \mathrm{~min})$, and then electrophoresed $(25 \mathrm{~V} / 300 \mathrm{~mA}$ for $25 \mathrm{~min}$ ). All manipulations were performed under minimal illumination. After electrophoresis, the slides were neutralized (0.4 M Tris-HCl; pH 7.5) for 5 min.

Dried microscope slides were stained with ethidium bromide $(2 \mu \mathrm{g} / \mathrm{ml}$ in distilled water; $70 \mu \mathrm{l} /$ slide $)$, covered and then viewed under fluorescence microscopy (×200, Leica DM1000, Germany). The microscope was capable of detecting epifluorescence and was equipped with a rhodamine filter (excitation wavelength $546 \mathrm{~nm}$; barrier $580 \mathrm{~nm}$ ). The extent of extranuclear fluorescence was scored (by eye) in 50 random cells of each sample, using a scale of $0-4$ as previously described by Kobayashi et al. [30]. Scoring was as follows: $0=$ no tail, $1=$ a comet tail more than half the width of the nucleus, 2 = a comet tail equal to the width of the nucleus, $3=$ a comet tail longer than the width of the nucleus but not twice as long and $4=$ a comet tail more than twice the width of the nucleus. This type of scoring has been shown to be as accurate as that afforded by computerized image analysis [31]. All slides were coded and scored in a blinded manner. A visual score for each class of subjects was calculated by multiplying the percentages of cells in the various comet classes by the score for that class. The total visual comet score reflecting the extent of DNA damage was the sum of scores for all 5 comet classes. Thus, a total visual score could range from 0 (all undamaged) to 400 (all maximally damaged) in arbitrary units (a.u.; fig. 1).

\section{Measurement of TOS}

Plasma TOS was measured using an automated method developed by Erel [26]. Oxidants present in a sample oxidize the ferrous ion of an o-dianisidine complex to ferric ion. Oxidation is enhanced by glycerol, which is abundant in the reaction medium, and the ferric ion forms a colored complex with xylenol orange under acidic conditions. Color intensity (which can be measured spectrophotometrically) is associated with the total level of oxidants present. Hydrogen peroxide is used to calibrate the assay, and results are expressed in terms of micromoles of hydrogen peroxide equivalent per liter $\left(\mu \mathrm{mol} \mathrm{H}_{2} \mathrm{O}_{2}\right.$ equiv/l). 
Table 1. Demographic and clinical data of the study and control groups

\begin{tabular}{lllll}
\hline & $\begin{array}{l}\text { Group I } \\
(\mathrm{n}=31)\end{array}$ & $\begin{array}{l}\text { Group II } \\
(\mathrm{n}=32)\end{array}$ & $\begin{array}{l}\text { Control group } \\
(\mathrm{n}=40)\end{array}$ & p value \\
\hline Age, years & $8.7 \pm 3.1$ & $8 \pm 3.1$ & $8.9 \pm 3.3$ & $>0.05$ \\
Gender, male/female & $15 / 16$ & $16 / 16$ & $19 / 21$ & $>0.05$ \\
BMI & $17.4 \pm 2.7$ & $16.9 \pm 1.4$ & $18 \pm 2.1$ & $>0.05$ \\
Symptom duration, years & $1.6 \pm 0.8$ & $1.8 \pm 0.8$ & - & $>0.05$ \\
Concurrent allergic rhinitis & $14 / 31(45 \%)$ & $15 / 32(47 \%)$ & - & $>0.05$ \\
Concurrent atopic dermatitis & $4 / 31(13 \%)$ & $6 / 32(19 \%)$ & - & $>0.05$ \\
SPT positivity to aeroallergens & $18 / 31$ & $23 / 32$ & - & $>0.05$ \\
FEV,$\%$ predicted & $87 \pm 4.4$ & $88 \pm 7$ & - & $>0.05$ \\
IgE, IU/l & $206.6 \pm 302.5$ & $369 \pm 468.2$ & - & \\
\hline
\end{tabular}

Values are represented as means \pm SD or $\mathrm{n} /$ total number of patients. SPT $=$ Skin-prick test.

Table 2. Results of TOS, TAS, OSI and DNA damage parameters study and control groups

\begin{tabular}{lrrr}
\hline & Group I & Group II & $\begin{array}{l}\text { Control } \\
\text { group }\end{array}$ \\
\hline TOS, $\mu$ mol $\mathrm{H}_{2} \mathrm{O}_{2}$ equiv/l & $13.1 \pm 4.0$ & $11.1 \pm 4.1$ & $6.3 \pm 3.5$ \\
TAS, mmol Trolox equiv/l & $1.4 \pm 0.5$ & $1.5 \pm 0.5$ & $2.7 \pm 0.6$ \\
OSI, a.u. & $12.4 \pm 8.6$ & $9.4 \pm 7.6$ & $3.0 \pm 4.4$ \\
DNA damage, a.u. & $18.2 \pm 1.0$ & $16.7 \pm 8.3$ & $13.7 \pm 3.4$ \\
\hline
\end{tabular}

\section{Measurement of TAS}

Plasma TAS was measured using another automated method developed by Erel [27]. This involves production of the hydroxyl radical, which is a potent biological reactant. A ferrous ion solution (reagent 1 ) is mixed with hydrogen peroxide (reagent 2). Radicals produced by the hydroxyl radical, including the brown dianisidinyl radical cation, are also potent in biological terms. Thus, it is possible to measure the antioxidative capacity of a sample in terms of the inhibition of free-radical reactions initiated by the production of the hydroxyl radical. Variation in assay data is very low $(<3 \%)$, and results are expressed as millimoles of Trolox equivalent per liter (mmol Trolox equiv/l).

\section{Measurement of Oxidative Stress Index}

The oxidative stress index (OSI) was the TOS-to-TAS ratio, and was calculated as follows: OSI (a.u.) $=$ TOS $\left(\mu \mathrm{mol} \mathrm{H}_{2} \mathrm{O}_{2} / \mathrm{l}\right) / \mathrm{TAS}$ (mmol Trolox/l).

\section{Statistics}

Data were expressed as mean \pm standard deviation (SD). Data were analyzed using SPSS for Windows v16.0. The $\chi^{2}$ analysis was used to compare categorical data. Comparison between group means was carried out using one-way ANOVA, the post hoc Tukey test and the Mann-Whitney $U$ test. $\mathrm{p}<0.05$ was considered statistically significant.

\section{Results}

Demographic and clinical data of the study group and the control group are shown in table 1 . The mean age of the patients in group I, group II and the controls was $8.7 \pm 3.1,8.0 \pm 3.1$ and $8.9 \pm 3.3$ years, respectively. There were no significant differences between groups with respect to age, gender and BMI. There were also no significant differences between group I and group II in terms of clinical parameters including concurrent allergic rhinitis or atopic dermatitis, symptom duration time, $\mathrm{FEV}_{1}$, aeroallergen sensitivity and total IgE levels $(\mathrm{p}>0.05)$.

Groups I and II had statistically significant elevated TOS levels and OSI compared with the control group $(\mathrm{p}<0.001)$, but there were no differences between groups I and II ( $p>0.05)$. TAS levels were low in both asthmatic groups compared with the control group $(\mathrm{p}<0.001)$, but here there was also no difference between groups I and II ( $p>0.05)$. Group I had elevated DNA damage compared with the control group $(\mathrm{p}<0.05)$, but there was no difference here between group II and the control group ( $p>$ $0.05)$. In addition, there were no differences in DNA damage between group I and group II ( $p>0.05$; table 2; fig. 2).

\section{Discussion}

This is the first study in the literature to show that 6-month montelukast monotherapy did not improve the corrupted oxidative stress parameters or the increased DNA damage that occurs in mild persistent asthma. Results show that both newly diagnosed (group I) and mon- 


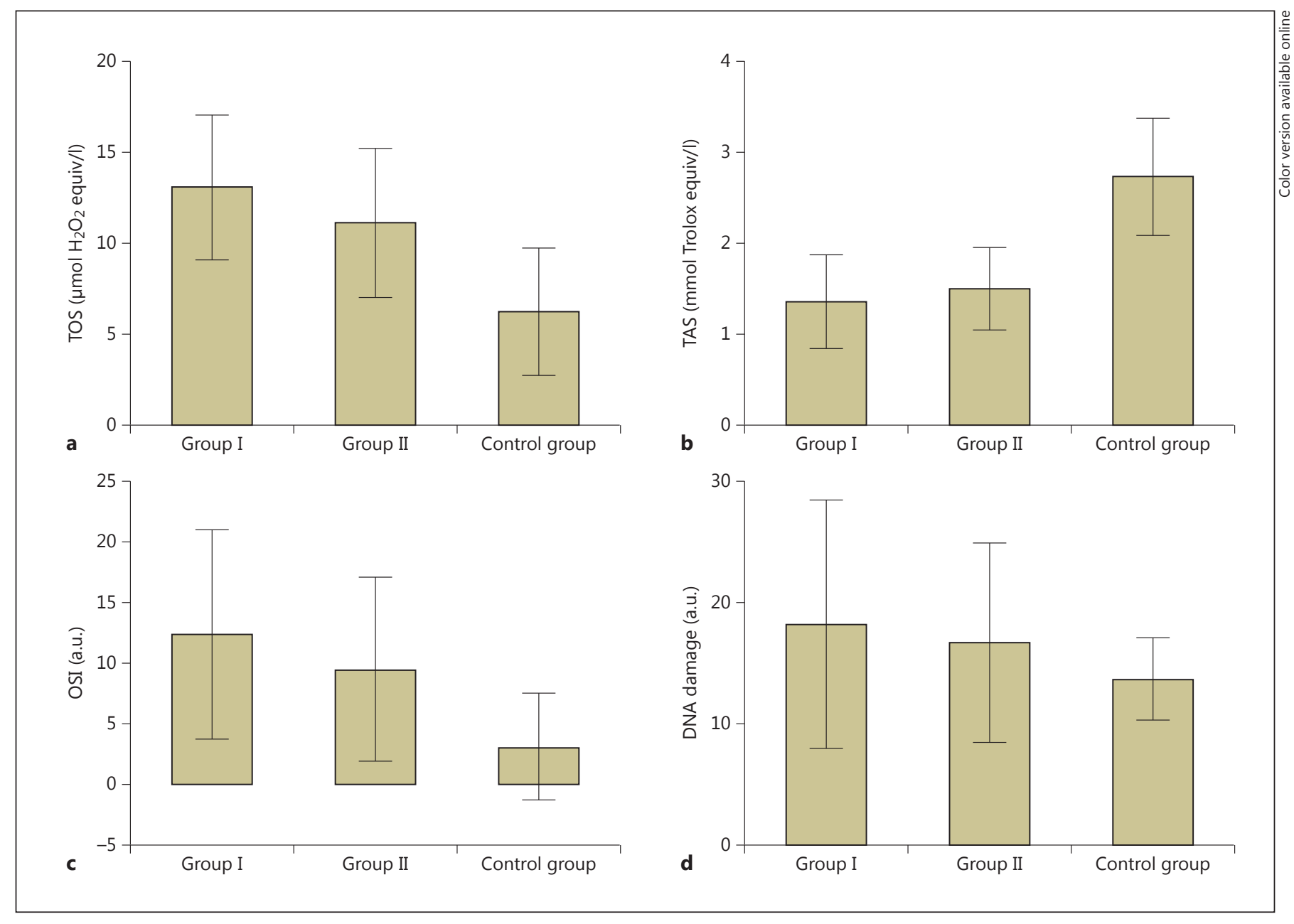

Fig. 2. TOS (a), TAS (b), OSI (c) and DNA damage (d) levels in the study and control groups.

telukast-treated asthmatic patients (group II) had statistically significant elevated TOS levels and OSI values and decreased TAS levels compared with the control group. In group I, DNA damage was high when compared with the control group, but there was no difference between the other 2 groups $(p>0.05)$. Montelukast therapy made a minimal but not statistically significant improvement in all these parameters.

Montelukast is a widely used agent for allergic diseases in both monotherapy and add-on therapy. The GINA guideline recommends montelukast at step 2 as an alternative drug to inhaled corticosteroids (ICS) and as an add-on therapy option for later treatment steps for all ages. However, the guideline states that montelukast only modestly reduces asthma symptoms and the need for oral corticosteroids compared with placebo in young children. Although regular montelukast treatment can im- prove some asthma outcomes compared to placebo, it does not reduce the frequency of hospitalization, courses of prednisone or the number of symptom-free days in children with recurrent, viral-induced wheezing [1]. Animal studies show that montelukast has a beneficial effect on oxidative stress-mediated conditions like ischemiareperfusion injury [32], drug intoxication $[33,34]$ and lipopolysaccharide-induced oxidative stress [35]. Al Saadi et al. [25] reported that montelukast decreased the ROS production in the whole blood and in isolated human polymorphonuclear neutrophils in asthmatic children. It also can decrease the production of reactive nitrogen species (e.g. NO) in children with asthma [36, 37].

Although there is a lack of comparative human studies on the impact of montelukast versus ICS therapy on the oxidative stress parameters and DNA damage, there are studies implying that ICS and ICS $+\beta_{2}$-mimetic combi- 
nations can decrease oxidative stress [19-21, 38]. However, in the current literature, there is no study evaluating the possible effects of montelukast monotherapy on the TOS and TAS levels or DNA damage. Our study is the first human clinical study on this subject.

The oxidant burden produced by eosinophils is substantial because these cells possess a several times greater capacity for generating $\mathrm{O}_{2}{ }^{-}$and $\mathrm{H}_{2} \mathrm{O}_{2}$ than neutrophils, and the content of eosinophil peroxidase in the eosinophils is several times higher than that of myeloperoxidase in the neutrophils (peroxidases are enzymes that catalyze the conversion of $\mathrm{H}_{2} \mathrm{O}_{2}$ and the $\mathrm{Cl}^{-}$ion to $\mathrm{HOCl}$ ). Therefore, eosinophils, which are present in increased numbers in the airways of asthmatic patients, play a major role in the generation of ROS in airway inflammation [3]. The oxidative and antioxidative systems have many members, and the half-life of ROS is usually short. The individual measurement of these molecules is time-consuming, costly and requires complicated techniques. In contrast, TOS and TAS are rapid, easy, reliable, sensitive and inexpensive methods for assessing oxidative stress, and they have shown good correlation with other oxidative stress markers [26, 27, 39].

Studies show that inflammation and oxidative stress are quite prevalent, not only in the lungs but also in the systemic circulation of asthmatics. Takemura et al. [40] demonstrated that serum C-reactive protein levels correlated negatively with indices of lung function and positively with sputum eosinophil counts. In the study of Nadeem et al. [41], plasma total antioxidant capacity and total protein sulfhydryls were found to be decreased in acute exacerbations of asthma when compared to stable asthmatic patients. They concluded that acute exacerbations of asthma are associated with increased oxidative stress, which is evident from some of the parameters in the plasma.

In our opinion, oxidative stress in asthma management should be discussed in 3 separate categories: (1) current asthma control, (2) long-term prevention of asthma complications and (3) prevention of DNA damage, genotoxicity and possible carcinogenesis. ROS can cause direct contraction of airway smooth-muscle preparations, an increased contractile response to methacholine and other substances, decreased numbers and functioning of $\beta$-adrenergic receptors, increased permeability, increased mucus production, an influx of inflammatory cells and an altered release of inflammatory mediators. ROS can also directly stimulate histamine release from mast cells $[3,42$, 43 ], and they play an important role in glucocorticoid resistance and severe asthma [44]. Bucchieri et al. [45] re- vealed that asthmatic bronchial epithelium is more susceptible to oxidant-induced apoptosis. In yet another study, the authors found that oxidative and nitrosative stress result in the loss of superoxide dismutase (SOD) activity [46]. In addition, in the oxidative and NO-rich environment of asthmatic airways, SOD inactivation triggers apoptosis and the loss of airway epithelial cells, which contributes significantly to airway remodeling.

Zeyrek et al. [22] reported higher TOS and TAS levels and greater DNA damage in a population of pediatric asthma patients than in controls. In our study, TAS levels were decreased compared with the control group, probably because of being used to balance oxidative stress. In another study, Hasbal et al. [23] reported high DNA strand breaks and reduced glutathione levels in pediatric asthmatics compared with healthy controls. After the treatment, that contained ICS + LT receptor antagonist + systemic antihistaminic and inhaled $\beta_{2}$-mimetic if necessary, the DNA strand breaks were found to have decreased. From this study, it is not clear whether ICS or LT receptor antagonist is responsible for the improvement. These beneficial effects of therapy are likely owing to ICS alone.

Obviously, it would have been preferable to perform this study in a randomized, controlled manner. However, in our country, we cannot afford the stringent requirements and ethical issues of prospective drug studies. We therefore planned the study in a case-control format. If we had obtained pre- and post-TAS, TOS and DNA damage samples from the montelukast therapy group (group II) or could have restudied the results of these parameters in group I, our results would have been more rigorously tested and impressive. However, we studied these parameters in a newly diagnosed asthmatic group (group I) for comparison with the main study group who had been taking montelukast for at least 6 months (group II). The results from group I provided an adequate idea about the pretreatment status of group II. We also want to highlight that this was a pivotal study; larger prospective studies are needed on this issue.

In conclusion, this is the first study to reveal that montelukast monotherapy cannot overcome oxidative stress and DNA damage in mild, intermittent pediatric asthma. Although further studies are needed, we managed to establish that the mechanisms of oxidative stress and the DNA damage are not necessarily affected by a 6-month montelukast monotherapy in children with mild persistent asthma. However, for a better understanding of this pathogenesis and these mechanisms, additional in vivo and in vitro studies are indeed required. 


\section{Acknowledgement}

The authors thank Miss. Huri Dedeakayogullari, Mr. Ersin Karatas and Mr. Eray Metin Guler for their assistance. This work was supported by a grant from the Bezmialem Vakif University.

\section{Disclosure Statement}

There were no conflicts of interest.

\section{References}

1 Global Initiative for Asthma (GINA) 2014. 15 Suzuki M, Kato M, Kimura H, Fujiu T, Morihttp://www.ginasthma.org/.

$\checkmark 2$ Riedl MA, Nel AE: Importance of oxidative stress in the pathogenesis and treatment of asthma. Curr Opin Allergy Clin Immunol 2008;8:49-56.

3 Park HS, Kim SR, Lee YC: Impact of oxidative stress on lung diseases. Respirology 2009;14: 27-38.

4 Nadeem A, Siddiqui N, Alharbi NO, Alharbi MM: Airway and systemic oxidant-antioxidant dusregulation in asthma: a possible scenario of oxidant spill over from lung into blood. Pulm Pharmacol Ther 2014;29:31-40.

5 Sawa T, Ohshima H: Nitrative DNA damage in inflammation and its possible role in carcinogenesis. Nitric Oxide 2006;14:91-100.

6 Wiseman H, Halliwell B: Damage to DNA by reactive oxygen and nitrogen species: role in inflammatory diseases and progression to cancer. Biochem J 1996;313:17-29.

7 Zuo L, Otenbaker NP, Rose BA, Salisbury KS: Molecular mechanism of reactive oxygen species-related pulmonary inflammation and asthma. Mol Immunol 2013;56:57-63.

-8 Zuo L, Koozechian MS, Chen LL: Characterization of reactive nitrogen species in allergic asthma. Ann Allergy Asthma Immunol 2014; 112:18-22.

-9 Braccioni F, Dorman SC, O’byrne PM, et al: The effect of cysteinyl leukotrienes on growth of eosinophil progenitors from peripheral blood and bone marrow of atopic subjects. J Allergy Clin Immunol. 2002;110:96-101.

10 Möhle R, Bautz F, Denzlinger C, Kanz L: Transendothelial migration of hematopoietic progenitor cells. Role of chemotactic factors. Ann NY Acad Sci 2001;938:26-34.

11 Peters-Golden M, Gleason MM, Togias A: Cysteinyl leukotrienes: multi-functional mediators in allergic rhinitis. Clin Exp Allergy 2006:36:689-703.

-12 Spada CS, Woodward DF, Hawley SB, Nieves AL: Leukotrienes cause eosinophil emigration into conjunctival tissue. Prostaglandins 1986;31:795-809.

13 Lee E, Robertson T, Smith J, Kilfeather S: Leukotriene receptor antagonists and synthesis inhibitors reverse survival in eosinophils of asthmatic individuals. Am J Respir Crit Care Med 2000;161:1881-1886.

14 Mori M, Takaku Y, Kobayashi T, Hagiwara K, Kanazawa M, Nagata M: Eosinophil superoxide anion generation induced by adhesion molecules and leukotriene D4. Int Arch Allergy Immunol 2009;149:31-38 kawa A: Inhibition of human eosinophil activation by a cysteinyl leukotriene receptor antagonist (pranlukast; ONO-1078). J Asthma 2003;40:395-404.

16 Kushiya M, Saito K, Kikuchi I, Kobayashi T, Hagiwara K, Kanazawa M, Nagata M: Differential effects of salbutamol and montelukast on eosinophil adhesion and superoxide anion generation. Int Arch Allergy Immunol 2006; 140:17-22.

17 Cho KJ, Seo JM, Lee MG, Kim JH: BLT2 is upregulated in allergen-stimulated mast cells and mediates the synthesis of Th2 cytokines. J Immunol 2010;185:6329-6337.

18 Cho KJ, Seo JM, Kim JH: Bioactive lipoxygenase metabolites stimulation of NADPH oxidases and reactive oxygen species. Mol Cells 2011:32:1-5.

19 Ozaras R, Tahan V, Turkmen S, Talay F, Besirli K, Aydin S, Uzun H, Cetinkaya A: Changes in malondialdehyde levels in bronchoalveolar fluid and serum by the treatment of asthma with inhaled steroid and beta2-agonist. Respirology 2000;5:289-292.

20 Saleh D, Ernst P, Lim S, Barnes PJ, Giad A: Increased formation of the potent oxidant peroxynitrite in the airways of asthmatic patients is associated with induction of nitric oxide synthase: effect of inhaled glucocorticoid. FASEB J 1998;12:929-937.

21 Antczak A, Kurmanowska Z, Kasielski M, Nowak D: Inhaled glucocorticosteroids decrease hydrogen peroxide level in expired air condensate in asthmatic patients. Respir Med 2000;94:416-421.

22 Zeyrek D, Cakmak A, Atas A, Kocyigit A, Erel O: DNA damage in children with asthma bronchiale and its association with oxidative and antioxidative measurements. Pediatr Allergy Immunol 2009;20:370-376.

23 Hasbal C, Aksu BY, Himmetoglu S, Dincer Y, Koc EE, Hatipoglu S, Akcay T: DNA damage and glutathione level in children with asthma bronchiale: effect of antiasthmatic therapy. Pediatr Allergy and Immunol 2010;21:e674e678.

24 Tsuboi H, Kouda K, Takeuchi H, Takigawa M, Masamoto Y, Takeuchi M, Ochi H: 8-hydroxydeoxyguanosine in urine as an index of oxidative damage to DNA in the evaluation of atopic dermatitis. Br J Dermatol 1998;138: 1033-1035.

25 Al Saadi MM, Meo SA, Mustafa A, Shafi AL, Tuwaijri AS: Effects of montelukast on free radical production in whole blood and isolat- ed human polymorphonuclear neutrophils (PMNs) in asthmatic children. Saudi Pharm J 2011;19:215-220.

26 Erel O: A new automated colorimetric method for measuring total oxidant status. Clin Biochem 2005:38:1103-1111.

27 Erel O: A novel automated direct measurement method for total antioxidant capacity using a new generation, more stable ABTS radical cation. Clin Biochem 2004:37:277285.

28 Polgar G, Promadhat V: Pulmonary Function Testing in Children: Techniques and Standards. Philadelphia, WB Saunders, 1971.

29 Singh NP, McCoy MT, Tice RR, Schneider EL: A simple technique for quantitation of low levels of DNA damage in individual cells. Exp Cell Res 1988:175:184-191.

30 Kobayashi H, Sugiyama C, Morikawa Y, Hayashi M, Sofuni TA: Comparison between manual and microscopic analysis and computerized image analysis in single cell electrophoresis assay. MMS Commun 1995;3:103115.

-31 Kocyigit A, Keles H, Selek S, Guzel S, Celik H, Erel O: Increased DNA damage and oxidative stress in patients with cutaneous leishmaniasis. Mutat Res 2005;585:71-78.

-32 Duran A, Otiük H, Terzi EH, Tosun M, Oziiü H, Ocak T, Kiiüer A: Protective effect of montelukast, a cysteinyl leukotriene receptor-1 antagonist, against intestinal ischemia-reperfusion injury in the rat. Acta Chir Belg 2013; 113:401-405.

33 Otunctemur A, Ozbek E, Cekmen M, Cakir SS, Dursun M, Polat EC, Somay A, Ozbay N: Protective effect of montelukast which is cysteinyl-leukotriene receptor antagonist on gentamicin-induced nephrotoxicity and oxidative damage in rat kidney. Ren Fail 2013;35: 403-410.

34 Ahmed AA: Protective effect of montelukast on paraquat-induced lung toxicity in rats. Biosci Trends 2009;3:63-72.

-35 Mohamadin AM, Elberry AA, Elkablawy MA, Gawad HS, Al-Abbasi FA: Montelukast, a leukotriene receptor antagonist abrogates lipopolysaccharide-induced toxicity and oxidative stress in rat liver. Pathophysiology 2011; 18:235-242.

36 Stelmach I, Ożarek-Hanc A, Zaczeniuk M, et al: Do children with stable asthma benefit from addition of montelukast to inhaled corticosteroids: randomized, placebo controlled trial. Pulm Pharmacol Ther 2015;31: $42-48$.
Effect of Montelukast on Oxidative Stress Parameters
Int Arch Allergy Immunol 2015;167:119-126 DOI: $10.1159 / 000436967$ 
37 Radwan ZM, Nasser Yamamah GA, Shaaban $\mathrm{HH}$, et al: Effect of different monotherapies on serum nitric oxide and pulmonary functions in children with mild persistent asthma. Arch Med Sci 2010;6:919-925.

38 Bodini A, Peroni DG, Zardini F, Corradi M Alinovi R, Boner AL, Piacentini GL: Flunisolide decreases exhaled nitric oxide and nitrotyrosine levels in asthmatic children. Mediators Inflamm 2006;2006:31919.

>39 Emin O, Hasan A, Aysegul D, Rusen D: Total antioxidant status and oxidative stress and their relationship to total IgE levels and eosinophil counts in children with allergic rhinitis. J Investig Allergol Clin Immunol 2012; 22:188-192.
40 Takemura M, Matsumoto H, Niimi A, Ueda T, Matsuoka H, Yamaguchi M, Jinnai $M$, Muro S, Hirai T, Ito Y, et al: High sensitivity C-reactive protein in asthma. Eur Respir J 2006;27:908-912.

41 Nadeem A, Raj HG, Chhabra SK: Increased oxidative stress in acute exacerbations of asthma. J Asthma 2005:42:45-50.

42 Henricks PAJ, Nijkamp FP: Reactive oxygen species as mediators in asthma. Pulm Pharmacol Ther 2001;14:409-420.

43 Bowler RP, Crapo JD: Oxidative stress in allergic respiratory diseases. J Allergy Clin Immunol 2002;110;349-356.
4 Barnes PJ: Corticosteroid resistance in patients with asthma and chronic obstructive pulmonary disease. J Allergy Clin Immunol 2013;131:636-645.

45 Bucchieri F, Puddicombe SM, Lordan JL, Richter A, Buchanan D, Wilson SJ, et al: Asthmatic bronchial epithelium is more susceptible to oxidant-induced apoptosis. Am J Respir Cell Mol Biol 2002;27:179-185.

46 Comhair SAA, Xu W, Ghosh S, Thunnissen FBJM, Almasan A, Calhoun WJ, et al: Superoxide dismutase inactivation in pathophysiology of asthmatic airway remodeling and reactivity. Am J Pathol 2005;166:663-674. 